\title{
ADSORPSI METILEN BLUE PADA KARBON AKTIF DARI BAN BEKAS DENGAN VARIASI KONSENTRASI NACL PADA SUHU PENGAKTIFAN $600^{\circ} \mathrm{C}$ DAN $650^{\circ} \mathrm{C}$
}

\section{Oleh:}

\author{
Anton Prasetyo ${ }^{1}$, Ahmad Yudi $^{2}$, Rini Nafsiati Astuti ${ }^{3}$
}

\begin{abstract}
Permintaan karbon aktif dunia tiap tahunnya mengalami peningkatan. Ditinjau dari komposisinya maka ban bekas mengandung unsur utama karbon, oleh karenanya mempunyai peluang untuk dijadikan karbon aktif. Salah satu parameter kualitas karbon aktif adalah daya adsorpsinya terhadap metilen blue oleh karenanya dalam penelitian akan dikaji daya adsorpsi karbon aktif terhadap metilen blue dengan aktivator kimia $\mathrm{NaCl}$ dan pada suhu pengaktifan $600{ }^{\circ} \mathrm{C}$ dan 650 ${ }^{\circ} \mathrm{C}$. Dari hasil penelitian didapatkan hasil bahwa bahwa kemampuan mengadsorpsi metilen blue meningkat dengan kenaikan konsentrasi activator kimia. Kemampuan mengadsorpsi didapatkan pada $\mathrm{NaCl}$ sebesar $30 \%$. Kemampuan adsorpsi juga meningkat dengan kenaikan suhu pengaktifan dengan suhu pengaktifan terbaik pada $650{ }^{\circ} \mathrm{C}$. Dari perbandingan hasil adsorpsi pada berbagai kondisi didapatkan hasil bahwa kemampuan adsorpsi terbesar karbon aktif adalah 18,9082 mg/g pada kondisi konsentrasi aktivator kimia $\mathrm{NaCl} 30 \%$ dan suhu pengaktifan $650{ }^{\circ} \mathrm{C}$. Analisis menggunakan SEM-EDAX menunjukkan permukaan pori karbon aktif yang masih belum terbuka secara sempurna dengan kandungan unsur karbon sebesar 95,41\%.
\end{abstract}

Kata Kunci: karbon aktif, ban bekas, $\mathrm{NaCl}$, Suhu Pengaktifan, adsorpsi, metilen blue

\section{PENDAHULUAN}

Karbon aktif merupakan golongan karbon amorph yang diproduksi dari bahan dasar dengan susunan senyawa mayoritas mengandung karbon (Mayer, dkk, 2005). Karbon aktif dapat digunakan untuk mengadsorbsi bahan yang berasal dari cairan maupun fasa gas (Ruiz, 2008). Daya adsorpsi tergantung pada besar atau volume pori-pori dan luas permukaan. Saat ini karbon aktif banyak digunakan sebagai bahan penyaring, pengolahan limbah, pengolahan air, dan banyak lagi aplikasinya. Dengan aplikasi yang luas dalam dunia industri maka permintaan dunia terhadap karbon aktif cukup besar di mana pada tahun 2005 sebesar 970.000 ton. Kebutuhan karbon aktif ini tiap tahun diperkirakan meningkat $5 \%$ dan pada tahun 2009 hingga tahun 2010 mencapai 1.200 .000 ton.

Dengan permintaan yang semakin meningkat maka mendorong banyak peneliti untuk mensintesis karbon aktif dari berbagai bahan. Sumber bahan mentah yang pernah dilakukan penelitian sebagai bahan karbon aktif diantaranya biji apricot, biji chery, biji

\footnotetext{
1,2,3 Jurusan Kimia Fakultas Sains dan Teknologi Universitas Islam Negeri Maulana Malik Ibrahim Malang Alamat korespodensi : antoniaprasetyo@gmail.com
} 
anggur, kulit kacang, kulit almond, tongkol jagung, kulit jagung dan ban bekas (Rao, et al, 2006).

Dengan meningkatnya jumlah kendaraan bermotor memberikan konsekuensi dengan banyaknya ban bekas. Jumlah ban bekas yang melimpah yang jika tidak dilakukan upaya pemanfaatan atau pengolahannya maka akan menimbulkan masalah lingkungan hidup dan salah satu penyelesaiannya adalah mengubah ban bekas menjadi karbon antif (Danny et, al, 2004). Banyaknya kandungan karbon dalam ban, membuat ban berpotensi dijadikan sebagai karbon aktif yang mempunyai daya adsorben yang tinggi. Penelitian tentang pemanfaatan ban bekas sebagai karbon aktif telah dilakukan beberapa peneliti. Ariyadejwanich et al (2002) dalam penelitiannya menjelaskan bahwa karbon aktif dari ban bekas yang dikarbonisasi pada temperatur 500 oC menghasilkan luas permukaan BET $737 \mathrm{~m} 2 / \mathrm{g}$.

Adsorbsi metilen blue telah banyak dilakukan untuk menentukan kapasitas adsorbsi karbon aktif. Penetapan ini bertujuan untuk mengetahui kemampuan arang aktif untuk menyerap larutan berwarna dan menentukan luas permukaan pori karbon aktif. Oleh karenanya kemampuan mengadsorpsi metilen blue menjadi salah satu ukuran kualitas dari metilen blue yang dihasilkan di mana SNI mensyaratkan kemampuan minimal menyerap adalah 120 mg/g untuk serbuk karbon aktif (Anonim, 1995).

Dalam penelitian ini akan dilakukan sintesis karbon aktif dari ban bekas dengan dengan menggunakan zat activator $\mathrm{NaCl}$ pada berbagai konsentrasi dan suhu pengaktifan pada $650{ }^{\circ} \mathrm{C}$ dan $700{ }^{\circ} \mathrm{C}$ dan selanjutnya dilakukan uji kualitasnya berdasarkan kemampuan karbon aktif dalam mengadsorpsi metilen blue.

\section{METODE PENELITIAN}

\section{Alat dan Bahan}

Alat yang digunakan dalam penelitian ini adalah oven, tanur, seperangkat alat gelas, fluidized bed reaktor, neraca analitik, piknomoter, hot plate, desikator, ayakan ukuran 120 mesh-250 mesh, spektrokopi UV-Vis.

Bahan utama yang digunakan dalam penelitian ini adalah ban bekas (waste tires). Bahan kimia yang digunakan dalam penelitian ini adalah natrium klorida $(\mathrm{NaCl})$ teknis, asam klorida ( $\mathrm{HCl}$, p.a), AgNO3, kertas saring, aluminium foil, aquades dan metilen blue.

\section{Cara Kerja}

\section{Karbonisasi}

Sampel berupa ban bekas dikarbonisasi dalam tanur pada temperatur awal $200{ }^{\circ} \mathrm{C}$ selama 30 menit. Setiap 30 menit temperatur dinaikkan dengan interval $50{ }^{\circ} \mathrm{C}$ sampai temperatur menjadi $500{ }^{\circ} \mathrm{C}$ agar ban bekas menjadi karbon. 


\begin{abstract}
Aktivasi Kimia
Karbon hasil proses karbonisasi diblender sampai halus kemudian diayak dengan menggunakan ayakan ukuran 120 mesh sampai 250 mesh. Karbon yang lolos dari 120 mesh dan tertahan pada ayakan 250 mesh ditimbang dan direndam dalam larutan natrium klorida dengan variasi konsentrasi $0 \%, 10 \%, 20 \%, 30 \%$, dan $35 \%$ selama 5 jam dengan ratio $1: 4(\mathrm{~b} / \mathrm{v})$ pada temperatur $80{ }^{\circ} \mathrm{C}$, kemudian disaring dan dikeringkan dalam oven pada temperatur $105^{\circ} \mathrm{C}$ selama 24 jam.
\end{abstract}

\title{
Aktivasi Fisika
}

Karbon yang telah terbentuk dan telah dilakukan aktivasi kimia dimasukkan dalam fluidized bed reactor dan dialiri $\mathrm{N}_{2}$ dengan kecepatan alir $200 \mathrm{~mL} / \mathrm{menit}$ dan diaktivasi pada variasi temperatur yakni $600{ }^{\circ} \mathrm{C}$ dan $650{ }^{\circ} \mathrm{C}$ selama 45 menit. Aktivasi fisika ini dilakukan di Laboratorium Kimia Fisika Universitas Gajah Mada Yogyakarta. Karbon aktif yang dihasilkan dicuci dengan $100 \mathrm{~mL} \mathrm{HCl} \mathrm{0,1} \mathrm{M} \mathrm{kemudian} \mathrm{dilanjutkan} \mathrm{dengan}$ pencucian menggunakan air panas sampai bebas $\mathrm{Cl}$ (dengan $\mathrm{AgNO}_{3} 0,1 \mathrm{~N}$ ) dan filtrat mempunyai $\mathrm{pH}$ netral ( $\mathrm{pH}$ 6-7). Setelah dicuci, karbon aktif dikeringkan pada temperatur $105^{\circ} \mathrm{C}$ selama 24 jam kemudian dikarakterisasi.

\section{Uji Adsorpsi Metilen Blue Pada Karbon Aktif}

Untuk mengetahui kemampuan adsorpsi karbon aktif maka dilakukan uji adsorpsi terhadap metilen blue. Penentuan daya adsorpsi karbon aktif terhadap metilen blue dengan menimbang karbon aktif sebanyak 0,1 gram lalu ditambahkan larutan metilen blue 100 ppm sebanyak $20 \mathrm{~mL}$ kemudian ditempatkan dalam erlenmeyer $50 \mathrm{ml}$ dan ditutup alumunium foil, sampel diaduk menggunakan magnetik stirrer selama 15 menit dan didiamkan selama 30 menit dengan kecepatan $100 \mathrm{rpm}$. Kemudian dilakukan penyaringan dan metilen blue sisa diukur konsentrasinya dengan metode spektroskopi UV-Vis. Pengukuran konsentrasi metilen blue dengan spektroskopi UV-Vis dilakukan pada panjang gelombang $664 \mathrm{~nm}$.

\section{Uji SEM-EDAX}

Untuk mengetahui morfologi permukaan dan kandungan unsur pada karbon aktif yang terbentuk, maka dilakukan Uji SEM EDAX. Uji tersebut dilakukan di Laboratorium Sentral FMIPA Universitas Negeri Malang.

\section{HASIL DAN PEMBAHASAN}

\section{Daya Serap terhadap Metilen Blue}

Kemampuan karbon aktif dalam mengsdsorbsi metilen blue merupakan salah satu standar kualitas karbon aktif menurut SNI. Berdasarkan Standar Industri Indonesia karbon aktif yang baik mampu menyerap metilen blue minimal $120 \mathrm{mg} / \mathrm{g}$ (Anonim, 1995).

Pengukuran larutan metilen blue dilakukan pada pada panjang gelombang $664 \mathrm{~nm}$. Hasil uji daya serap karbon aktif terhadap larutan metilen blue dengan konsentrasi 100 ppm menghasilkan nilai daya serap metilen blue sesuai data berikut: 
Tabel 1. Kemampuan daya serap karbon aktif terhadap metilen blue

\begin{tabular}{|c|c|c|}
\hline $\begin{array}{c}\text { Konsentrasi } \\
\mathrm{NaCl}(\%)\end{array}$ & $\begin{array}{c}\text { Daya adsorpsi metilen } \\
\text { blue } \\
\mathrm{T} 600{ }^{\circ} \mathrm{C}(\mathrm{mg} / \mathrm{g})\end{array}$ & $\begin{array}{c}\text { Daya adsorpsi metilen } \\
\text { blue } \\
\mathrm{T} 650{ }^{\circ} \mathrm{C}(\mathrm{mg} / \mathrm{g})\end{array}$ \\
\hline 0 & 17,4265 & 18,2614 \\
\hline 10 & 18,2990 & 18,4632 \\
\hline 20 & 18,4780 & 18,6612 \\
\hline 30 & 18,7490 & 18,9082 \\
\hline 35 & 18,2467 & \\
\hline
\end{tabular}

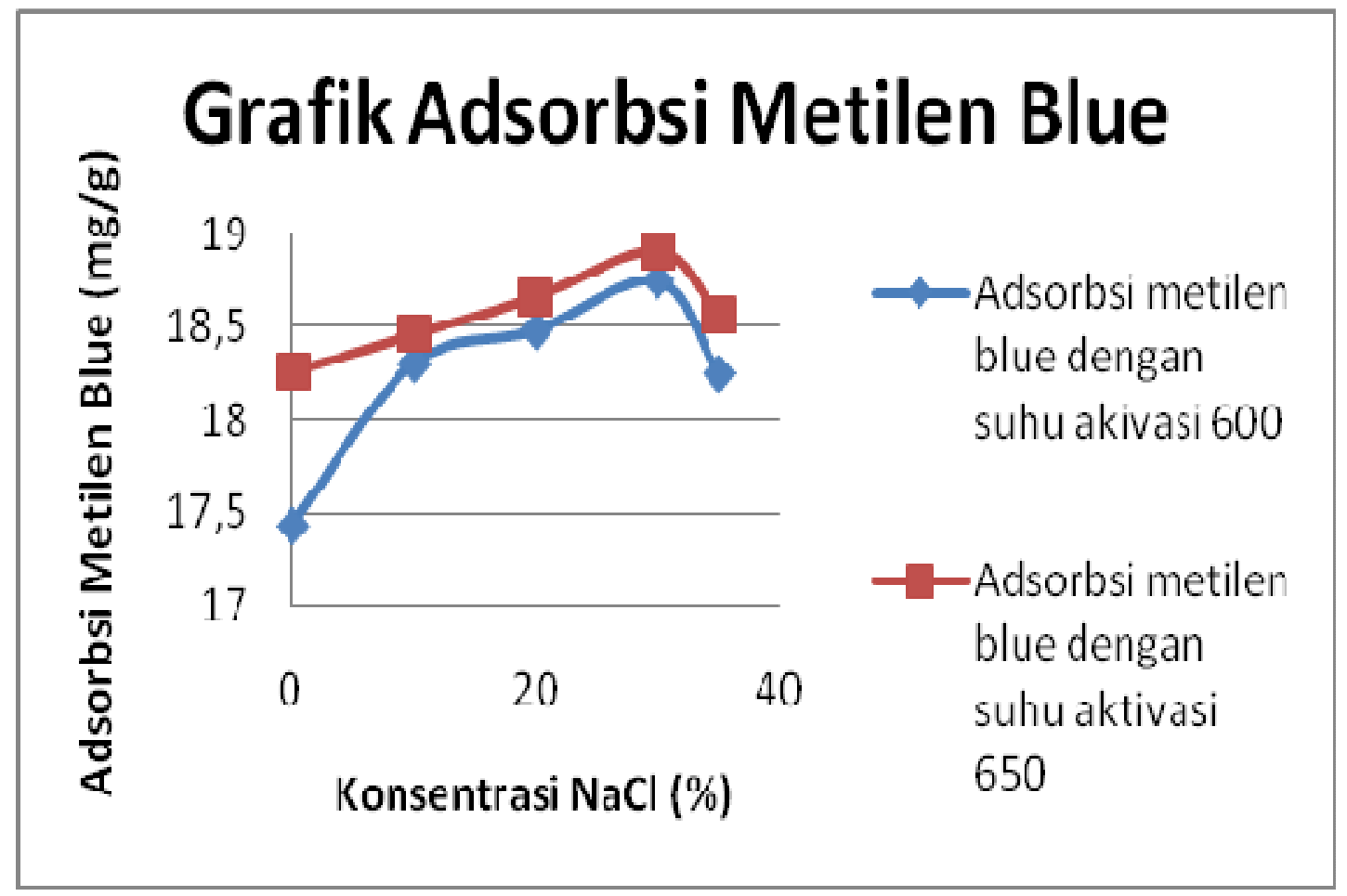

Gambar 1. Daya serap karbon aktif konsentrasi $\mathrm{NaCl}$ terhadap metilen blue variasi

Tabel 1 di atas menjelaskan bahwa berat metilen blue teradsorpsi menunjukkan nilai yang berbeda-beda pada masing-masing perlakuan aktivasi kimia maupun aktivasi fisika. Dari hasil adsorpsi diketahui bahwa dengan kenaikan kadar $\mathrm{NaCl}$ maka kemampuan adsorpsi semakin tinggi di mana kemampuan mengadsorpsi tertinggi ada pada konsentrasi $\mathrm{NaCl} 30 \%$ dan akan turun pada konsentrasi NaCL $35 \%$. Apabila dibandingkan dengan perbandingan suhu aktivasi maka diperoleh hasil bahwa suhu 650 oC memiliki kemampuan mengadsorpsi yang lebih baik dibandingkan dengan $600 \mathrm{oC}$. 
Karbon aktif yang tidak diaktivasi menggunakan $\mathrm{NaCl}$ menunjukkan hasil daya adsorpsi terkecil dari semua sampel yang dianalisis, dan kemampuan mengadsorpsi akan naik sampai pada konsentrasi $\mathrm{NaCl} 30 \%$ dan akan turun pada konsentrasi $\mathrm{NaCl} 35 \%$. Aktivator kimia umumnya berfungsi sebagai bahan pengaktif yang berfungsi untuk mendegradasi atau penghidrasi molekul organik selama proses karbonisasi, membatasi pembentukan tar, membantu dekomposisi senyawa organik pada aktivasi berikutnya, dehidrasi air yang terjebak dalam rongga-rongga karbon, membantu menghilangkan endapan hidrokarbon yang dihasilkan saat proses karbonisasi dan melindungi permukaan karbon sehingga kemungkinan terjadinya oksidasi dapat dikurangi (Manocha, 2003).

$\mathrm{NaCl}$ sebagai aktivator kimia mampu menekan pengotor hidrokarbon dan pengotor dalam pori karbon aktif menyebabkan semakin besarnya volume pori, selain itu $\mathrm{NaCl}$ mampu menghidrasi kandungan air yang ada dalam pori sehingga volume pori semakin besar. Dari penelitian didapatkan hasil bahwa semakin tinggi konsentrasi $\mathrm{NaCl}$ maka daya adsorpsi semakin tinggi, hal ini menunjukkan bahwa pori karbon aktif semakin besar sehingga kemampuan mengadsorpsi juga semakin besar. Akan tetapi $\mathrm{NaCl}$ yang berlebih menyebabkan $\mathrm{NaCl}$ sulit keluar dari pori karbon sehingga akan mempersempit volume pori karbon aktif. Hal ini terlihat dari karbon aktif yang diaktivasi kimia dengan $\mathrm{NaCl}$ $35 \%$ mempunyai daya adsorpsi metilen blue yang lebih kecil jika dibandingkan dengan karbon aktif yang diaktivasi $\mathrm{NaCl} 30 \%$ (konsentrasi terbaik). Ini disebabkan karena pada konsentrasi $35 \%$ telah terjadi keadaan jenuh (kandungan $\mathrm{NaCl}$ berlebih di permukaan karbon aktif) sehingga menghalangi proses penyerapan metilen blue.

Dalam aktivasi fisika terjadi proses pemutusan rantai karbon dari senyawa organik. (Sembiring, 2003). Aktivasi secara fisika biasanya digunakan uap air, gas karbon dioksida, oksigen, dan nitrogen. Gas-gas tersebut berfungsi untuk mengembangkan struktur rongga yang ada pada arang sehingga memperluas permukaannya, menghilangkan konstituen yang mudah menguap dan membuang produksi tar atau hidrokarbon-hidrokarbon pengotor pada arang. Dengan aktivasi fisika dapat dihasilkan karbon aktif yang memiliki luas permukaan dan pori dengan ukuran besar.(Swiatkowski, 1998).

Dari hasil penelitian didapatkan hasil bahwa karbon aktif yang diaktivasi fisika dengan suhu 650 oC mempunyai daya adsorpsi terhadap metilen blue yang lebih besar dari pada karbon aktif yang diaktivasi pada suhu 600 oC. Hal ini menandakan suhu pemanasan berpengaruh terhadap ukuran pori yang dihasilkan, di mana dengan pemanasan lebih tinggi maka ukuran pori menjadi lebih besar, sehingga daya adsorpsinya menjadi lebih besar.

\section{Karakteristik karbon dengan SEM-EDAX}

Pada penelitian ini dilakukan uji SEM - EDAX untuk mengetahui morfologi permukaan dan susunan unsur dari serbuk karbon aktif yang dihasilkan. Uji SEM dilakukan pada sampel yang memiliki kemampuan adsorpsi paling bagus yang dalam hal 
ini pada konsentrasi $\mathrm{NaCl} 30 \%$ dan suhu pengaktifan $650{ }^{\circ} \mathrm{C}$. Hasil uji SEM dengan perbesaran 10.000 dan 15.000 kali adalah seperti di bawah ini:

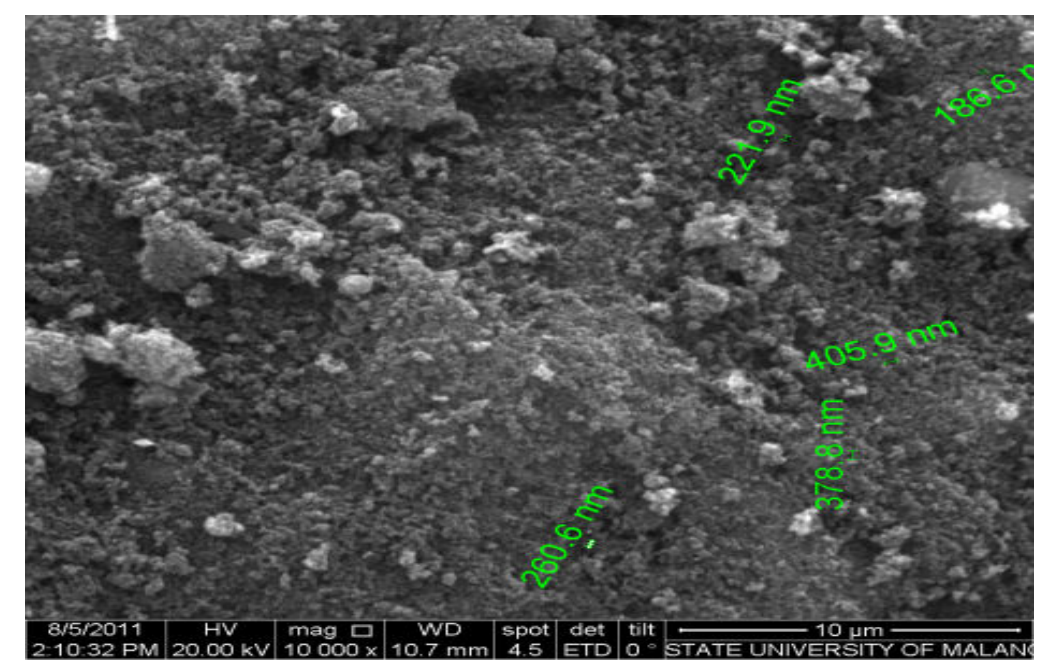

(a)

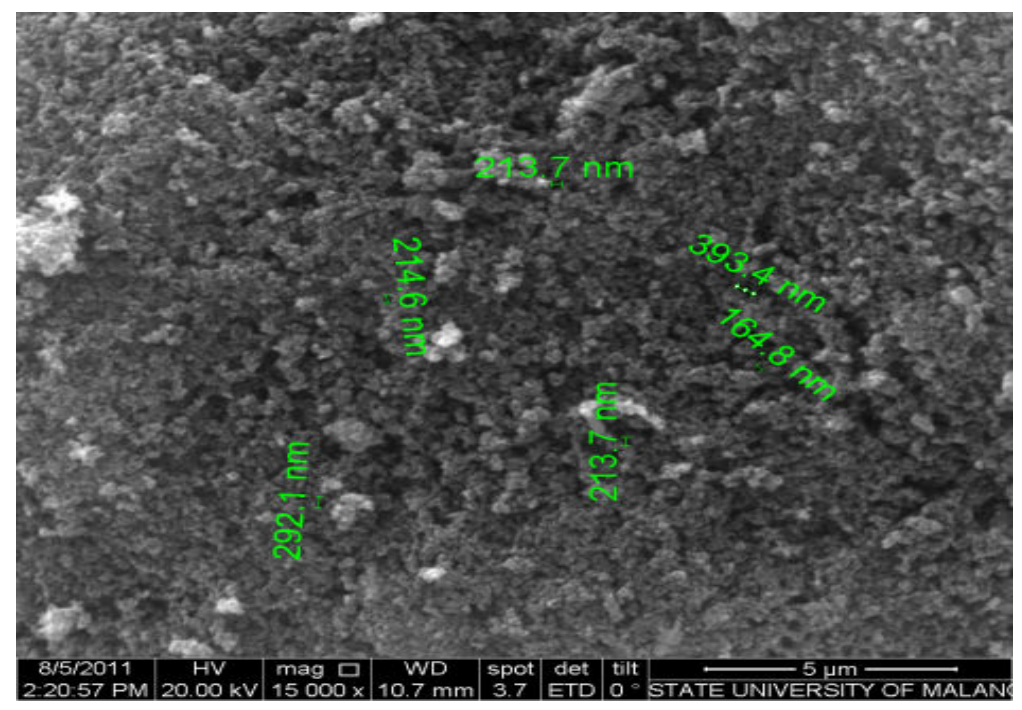

(b)

Gambar. 2. Hasil Uji SEM Karbon Aktif Dengan Konsentrasi NaCl $30 \%$ dan Suhu Aktivasi $650{ }^{\circ} \mathrm{C}$. (a) Perbesaran 10.000 kali; (b) Perbesaran 15.000.000 kali.

Pada gambar SEM-EDAX di atas menunjukkan bahwa karbon aktif yang dihasilkan mempunyai permukaan pori dengan rongga kecil dan rapat. Ukuran rongga yang kecil dan rapat ini, dimungkinkan karena proses aktivasi fisika yang kurang lama dan tinggi, sehingga proses pembukaan pori yang belum sempurna. Pada gambar juga diperlihatkan adanya bintik bintik putih, ini dimungkinkan adanya $\mathrm{NaCl}$ pada permukaan. Seharusnya $\mathrm{NaCl}$ masuk ke dalam pori, akan tetapi dengan pori yang terlampau kecil sehingga tidak bisa masuk dalam rongga. Ukuran pori ini tentunya akan mempengaruhi jumlah metilen blue yang terserap yang apabila dibandingkan dengan SNI maka masih lebih kecil di 
mana SNI mensyaratkan kemampuan mengadsorpsi metilen blue adalah minimal 120 $\mathrm{mg} / \mathrm{g}$.

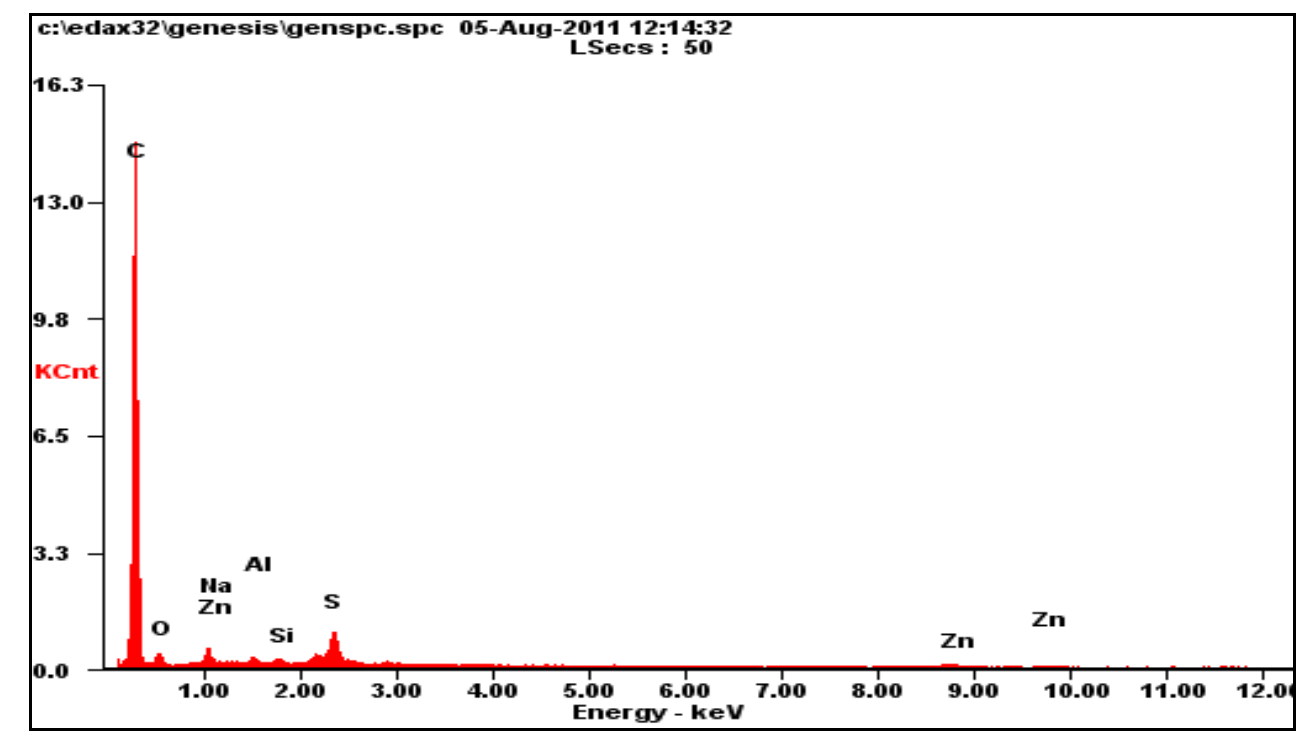

Gambar 3. Hasil Analisa EDAX Dari Karbon Aktif Yang Dihasilkan Pada Konsentrasi Aktivator $\mathrm{NaCl} 30 \%$ dan Suhu Aktivasi $650{ }^{\circ} \mathrm{C}$.

Sesuai difraktogram EDAX di atas dapat dilihat bahwa terdapat unsur unsur pengotor selain karbon pada sampel karbon aktif yang dihasilkan. Pengotor tersebut adalah belerang, silika, alumunium, natrium, seng dan oksigen. Akan tetapi jumlah persen unsur terbesar pada sampel karbon aktif adalah unsur karbon dengan prosentase sebesar 95,41\%. Unsur unsur pengotor tersebut dimungkinkan berasal dari mineral aditif pada proses pembuatan ban dan juga dari senyawa activator $\mathrm{NaCl}$.

\section{KESIMPULAN}

Dari hasil uji adsorpsi metilen blue terhadap karbon aktif dari ban bekas dengan activator $\mathrm{NaCl}$ dan suhu aktivasi $600{ }^{\circ} \mathrm{C}$ dan $650{ }^{\circ} \mathrm{C}$, diperoleh hasil bahwa kemampuan mengadsorpsi metilen blue terbesar adalah 18,9082 mg/g dengan kondisi konsentras activator kimia $30 \%$ dan suhu pengaktifan sebesar $650{ }^{\circ} \mathrm{C}$. Analisis menggunakan SEMEDAX menunjukkan permukaan pori karbon aktif yang masih belum terbuka secara sempurna dengan kandungan unsur karbon sebesar 95,41\%.

\section{DAFTAR PUSTAKA}

Anonim, 1995. Arang Aktif Teknis SNI 06-3730-1995. Badan Standardisasi Nasional. Jakarta 
Ariyadejwanich P, Tanthapanichakoon W , Nakagawa G, Mukai S.R, Tamon H, 2003 Preparation and characterization of mesoporous activated carbon from waste tires, Carbon 41 (2003) 157 - 164.

Danny C.K. Ko, Edward L.K. Mui, Ken S.T. Lau, Gordon McKay, Production of activated carbons from waste tire - process design and economical analysis, waste Management 24 (2004) 875 - 888

Jankowska, H., Swiatkowski, A., Choma, J. 1991. Active Carbon. London: Horwood.

Manocha, Satish M. 2003. Porous Carbons. India: Journal Sadhana vol 28, parts 1\&2.

Mayer, V.A,dkk. 2005. ASTM Dictionary of Engineering Science and Technology Tenth Edition. Amerika: ASTM International.

Rao M.Madhava, Rao Chandra G.P, Seshaiah K, Choudary N.V, Wang M.C, 2008 Activated carbon from Ceiba pentandra hulls, an agricultural waste,as an adsorbent in the removal of lead and zinc from aqueous solutions, Waste Management 28 (2008) $849-858$

Ruiz, Isabel.S and Crelling, John C. 2008. Applied Coal Petrology. Amsterdam: Elsevier. Swiatkowski, A., 1998, Adsorption and its Aplication in Industry and Environmental Protection Studies in Surface Science and Catalysis. Belanda: Elsivier. 